\title{
Mechanical Properties of Fiber Reinforced Polymer Composites
}

\author{
S.Ajith, C.Sivapragasam, V.Arumugaprabu, M.Bharathan, M.Bharathan, C.Deeliban
}

\begin{abstract}
The usage of composite materials has been increasing in all fields of manufacturing applications as it has tremendous mechanical properties. The variation in the property of the materials can be observed through the addition of matrices. Polyester, vinyl ester and epoxy are some of the resins which are commonly used as matrix in manufacturing composite materials. Hence this study intends to explore the mechanical properties such as impact and flexural for different fibers used in combination with different matrices. It is found that epoxy resin has higher impact $(334 \mathrm{~N} / \mathrm{mm} 2)$ and flexural strength (132 MPa) with bamboo fiber and polyester resin has higher impact $(24.2 \mathrm{~kJ} / \mathrm{m} 2)$ and flexural strength $(80.2 \mathrm{MPa})$ with pineapple leaf fiber.
\end{abstract}

\section{Keywords : Composites, Fibers, Matrix, Mechanical Properties.}

\section{INTRODUCTION}

$\mathrm{T}$ he application of composite materials have been increased in the field of automobiles, aircraft, maritime, sports equipment's etc. as these materials have excellent mechanical properties and are eco-friendly in nature. The properties include corrosion resistance, high strength, low density and reasonable cost [1-4]. In addition to these general properties composite materials are also flexible, high resistance to impact and minimum irritation to skin and respiratory tracts [5]. The two major phases of the composite materials are the matrix phase and the reinforcement phase. Due to high performance of the composite materials, they are also used in different erosive environment as they can withstand higher than traditional materials [6]. A topical research forecasted that the natural fiber composite materials has a total market value of about US\$289.3 million across the globe and it can double within three years [7]. Polymer composites made of natural fibers are renewable resources and its development [8] is shown in Fig. 1. Some of the natural fibers are jute, sisal, coir, pineapple leaf, kenaf, kapok, flax, hemp etc. [9]. As the fiber reinforced composites

Revised Manuscript Received on December 05, 2019.

* Correspondence Author

S. Ajith, Department of Civil Engineering, Kalasalingam Academy of Research and Education, Krishnankoil-626126, India. Email: ajith.s@klu.ac.in

C. Sivapragasam, Department of Civil Engineering, Kalasalingam Academy of Research and Education, Krishnankoil-626126, India. Email: sivapragasam@klu.ac.in

V. Arumugaprabu*, Department of Mechanical Engineering, Kalasalingam Academy of Research and Education, Krishnankoil-626126, India. Email: v.arumugaprabu@klu.ac.in

M.Bharathan, M.Bharathan and C.Deeliban, Department of Mechanical Engineering, Kalasalingam Academy of Research and Education, Krishnankoil - 626126, India. Email: bharathanmanni123@gmail.com, bharathroshen24@gmail.com, deeliban20@gmail.com are made of natural fibers they can be recycled and used again which won't affect the environment in any aspect. Hence this research intends to study and evaluate the mechanical properties such as impact and flexural strength of the natural fibers reinforced with epoxy and polyester matrix.

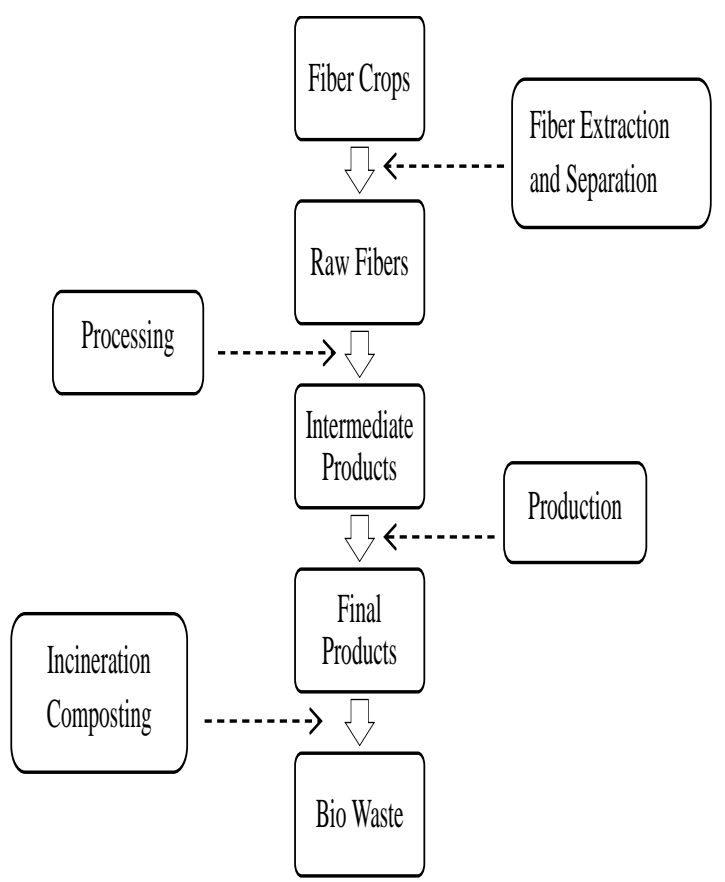

Fig. 1 Development of natural fibers from crops [8]

\section{FABRICATION OF SPECIMEN}

Most of the researchers adopted hand lay-up technique whereas some of the researchers used compression moulding technique. ASTM standards were followed for the dimension and testing of fabricated specimens. The steel mould is fully applied with wax or mould release spray for easy removal of the specimen. The fibers are placed in the mould and pre compression is done for suitable arrangement. If epoxy resin is used for fabrication appropriate amount of hardener is mixed and it is poured above the pre-compressed fibers. If polyester resin is used, methyl ethyl ketone peroxide which is a catalyst and cobalt napthalate which acts as an accelerator is added in certain proportions. Finally the specimen is to be compressed and cured for a period of 24 hours. Thus to know about the strength of materials, mechanical properties such as impact, flexural and tensile test are done as per ASTM standards. Scanning Electron Microscope (SEM) or morphology test is done to know about surface details of the composites or debonding the fibers and fiber matrix interaction $[10,11,12]$.

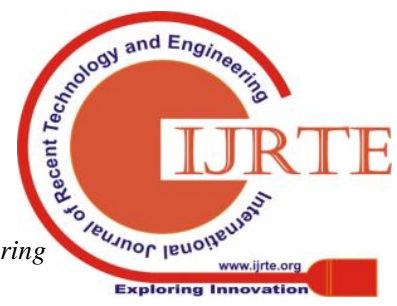




\section{MECHANICAL PROPERTIES OF NATURAL FIBERS REINFORCED WITH EPOXY MATRIX}

Epoxy resins are significant among the thermosetting polymers as they are used as adhesives in wider applications including aerospace. Researchers have been attracted by epoxy resin as they have enhanced mechanical properties such as mechanical response, thermal stability, electrical resistance, low density. But it is also known that epoxy resin fail in their mechanical properties due to improper curing agent. Hence mixing and curing ratio is also an important factor $[13,14]$. Epoxy resins are produced by combining epichlorohydrin with bisphenol. These resins also have good insulating properties, good environmental and chemical resistance [15].

\section{A. Comparison between Epoxy and Polyester Resin}

The general comparison between epoxy and polyester is listed in Table I. Both the resins have some distinct features. The strength of the materials can be determined when these resins are mixed with the fibers at certain proportions. After mixing both the fibers and resins compressing the specimen and allowing it to cure as per the standards also play a major role in manufacturing high strength materials.

Table I Difference Between Epoxy and Polyester Resin $[15,16]$

\begin{tabular}{|c|c|c|}
\hline S.No & Epoxy & Polyester \\
\hline 1. & $\begin{array}{l}\text { Relative strength is } 2000 \mathrm{lbs} \text {. } \\
\text { per square inch }\end{array}$ & $\begin{array}{l}\text { Relative strength is less than } 500 \\
\text { lbs. per square inch }\end{array}$ \\
\hline 2. & wear and crack & \\
\hline 3. & & \\
\hline 4. & High moisture resistant & Minor moisture resistant \\
\hline 5. & $\begin{array}{l}\text { Ventilation required while } \\
\text { using epoxy }\end{array}$ & $\begin{array}{l}\text { Ventilation required while using } \\
\text { polyester }\end{array}$ \\
\hline
\end{tabular}

6. Less odor High odor

The mechanical properties such as impact and flexural strength for different natural fibers are listed in Table 2. It is observed that carbon fiber reinforced with printed circuit board has high impact and flexural strength.

\section{B. Mechanical properties of natural fibers reinforced with polyester matrix}

The polyester resins have good resistance to chemicals, low density, reduced cost and high process ability. These resins are classified under thermosetting and have wide range of applications such as buildings, water pipes, automotive etc. [16]. To study the properties of polyester resin in various fibers, some researchers tested the fabricated specimen using water absorption test and then determined the mechanical properties.

Dhakal et. al [17] studied the mechanical properties of hemp fiber after water absorption. The specimens with the fiber content of $0,10,15,21 \& 26$ were fabricated and subjected to compression and curing. Then the specimen is immersed in water at different temperatures such $25^{\circ}$ Celsius and $100^{\circ}$ Celsius to determine the properties at varying time duration. Result shows that the percentage of water absorption increases due to increase in fiber content. This may be due to the cellulose and voids present in the fiber. Four layer of hemp fiber which has $21 \%$ of fiber weight exhibited high tensile modulus as $1.22 \mathrm{GPa}$ at dry, $0.62 \mathrm{GPa}$ at wet and flexural modulus of $7.30 \mathrm{GPa}$ at dry temperature.
The flexural modulus reduced at wet temperature at the same fiber content.

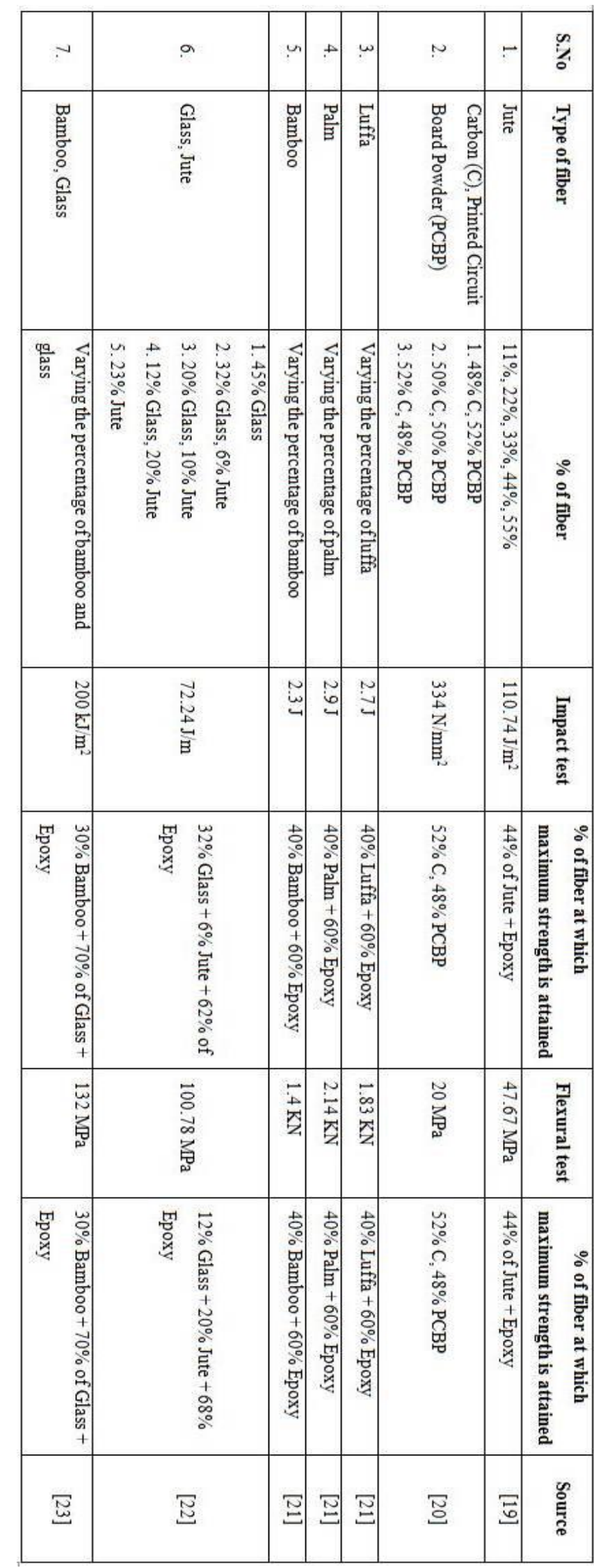

Table II Mechanical Properties of Natural fibers

Epoxy

Reinforced with

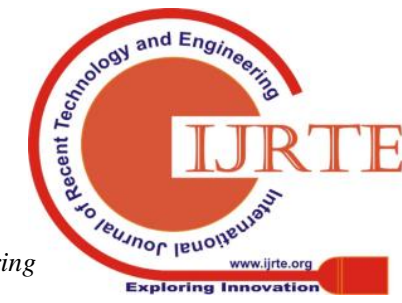


Sreekumar et. al [18] studied the mechanical properties of sisal polyester composites. Sisal fibers were chopped with an equal size of $30 \mathrm{~mm}$ length. Cobalt napthenate and methyl ethyl ketone peroxide of equal ratio such as 1 weight $\%$ was mixed with isophthalic polyester resin. Then this chemical mixture is passed into a closed mould at $1 \mathrm{~kg} / \mathrm{cm} 2$ of pressure. Six different samples of $40 \%$ fiber content which underwent heat treatment, benzoylation, permanganate treatment, silane treatment and mercerization were fabricated. Then the fabricated specimen is left for curing up to a period of 12 hours. Results showed that $40 \%$ fiber content which underwent silane treatment has good tensile and flexural strength as $76 \mathrm{MPa}$ and $105 \mathrm{MPa}$.

The impact and flexural strength of the different natural fibers reinforced with polyester resin is shown in Table 3 . It is noted that $30 \%$ of pineapple leaf fiber with polyester resin attained higher impact and flexural strength. It is also said that each natural fiber with different proportion of fibers and matrix can able to attain maximum impact and flexural strength.

\begin{tabular}{|c|c|c|c|c|c|c|c|}
\hline S.No & $\begin{array}{l}\text { Type of } \\
\text { fiber }\end{array}$ & $\%$ of fiber & $\begin{array}{l}\text { Impact } \\
\text { test }\end{array}$ & $\begin{array}{l}\text { \% of fiber at which } \\
\text { maximum strength is } \\
\text { attained }\end{array}$ & $\begin{array}{l}\text { Flexural } \\
\text { test }\end{array}$ & $\begin{array}{l}\% \text { of fiber at which } \\
\text { maximum strength } \\
\text { is attained }\end{array}$ & Source \\
\hline 1. & Jute & $\begin{array}{l}11 \%, 22 \%, 33 \%, 44 \%, \\
55 \%\end{array}$ & $\begin{array}{l}148.58 \\
\mathrm{~J} / \mathrm{m}^{2}\end{array}$ & $44 \%$ of Jute + Polyester & $20.23 \mathrm{MPa}$ & $\begin{array}{l}44 \% \text { of Jute + } \\
\text { Polyester }\end{array}$ & [19] \\
\hline 2. & Straw & $\begin{array}{l}\text { Varying the percentage } \\
\text { of straw in equal } \\
\text { proportion }\end{array}$ & $2.6 \mathrm{KJ} / \mathrm{m}^{2}$ & $30 \%$ & $47 \mathrm{MPa}$ & $30 \%$ of straw & [24] \\
\hline 3. & Sisal & $\begin{array}{l}\text { Varying the percentage } \\
\text { of sisal in equal } \\
\text { proportion }\end{array}$ & $11 \mathrm{KJ} / \mathrm{m}^{2}$ & $30 \%$ & $53 \mathrm{MPa}$ & $30 \%$ of sisal & [24] \\
\hline 4. & PALF & $\begin{array}{l}\text { Varying the percentage } \\
\text { of PALF in equal } \\
\text { proportion }\end{array}$ & $\begin{array}{l}24.2 \\
\mathrm{KJ} / \mathrm{m}^{2}\end{array}$ & $30 \%$ & $80.2 \mathrm{MPa}$ & $30 \%$ of PALF & [24] \\
\hline 5. & Coir & $10 \%, 17 \%, 25 \%, 33 \%$ & $967 \mathrm{~J} / \mathrm{m}$ & $25 \%$ & $61 \mathrm{MPa}$ & $25 \%$ & [25] \\
\hline 6. & $\begin{array}{l}\text { Napier } \\
\text { Grass }\end{array}$ & $\begin{array}{l}10 \%, 15 \%, 20 \%, 25 \%, \\
30 \%\end{array}$ & $\begin{array}{l}\text { Not } \\
\text { Reported }\end{array}$ & Not Reported & $39.5 \mathrm{MPa}$ & $25 \%$ & [26] \\
\hline
\end{tabular}

Table III Mechanical Properties of Natural Fibers Reinforced with Polyester

\section{CONCLUSION}

In this research the mechanical properties of different natural fibers reinforced with epoxy and polymer resin have been studied. It is noted that $52 \%$ of carbon fiber attained high impact strength and $30 \%$ of bamboo fiber attained high flexural strength with epoxy resin. It is also noted that $30 \%$ of PALF fiber attained high impact and flexural strength with polyester resin. Therefore it is concluded that each and every natural fiber with suitable proportions of fiber and resin can attain high mechanical properties but their applications may differ accordingly. As natural fibers are decomposable and environmental friendly this types of composites can be used in all fields of applications.

\section{REFERENCES}

1. S. Vigneshwaran, M. Uthayakumar \& V. Arumugaprabu, "A review on erosion studies of fiber-reinforced polymer composites". Journal of Reinforced Plastics and Composites, 36(14), 2017, pp. 1019-1027.

2. S. Vigneshwaran, M. Uthayakumar \& V. Arumugaprabu, "Review on Machinability of Fiber Reinforced Polymers: A Drilling Approach". Silicon, 10, 2018, pp. 2295-2305.

3. R. D. J. Johnson, V. Arumugaprabu \& T. J. Ko, "Mechanical Property, Wear Characteristics, Machining and Moisture Absorption
Studies on Vinyl Ester Composites-a Review”. Silicon, 2018, pp 1-16.

4. K. M. John, S. T. Kumaran, R. Kurniawan, K. Moon Park \& J. H Byeon, "Review on the methodologies adopted to minimize the material damages in drilling of carbon fiber reinforced plastic composites". Journal of Reinforced Plastics and Composites, 2018, 0731684418819822

5. N. Sgriccia, M. C. Hawley \& M. Misra, "Characterization of natural fiber surfaces and natural fiber composites". Composites Part A: Applied Science and Manufacturing, 39(10), 2008, pp. 1632-1637.

6. S. Vigneshwaran, M. Uthayakumar, V. Arumugaprabhu, A. Ramesh, K. Muthu Kumar \& K. Pasupathi, "Effect of chemical treatment on erosion properties of jute polyester composites". In AIP Conference Proceedings - AIP Publishing, Vol. 2057, No. 1, 2019, pp. 020063

7. O. Faruk, A. K. Bledzki, H. P. Fink \& M. Sain, "Progress report on natural fiber reinforced composites". Macromolecular Materials and Engineering, 299(1), 2014, pp. 9-26.

8. H. Singh, J. I. P. Singh, S. Singh, V. Dhawan, \& S. K. A. Tiwari, "Brief Review of Jute Fibre and Its Composites". Materials Today: Proceedings, 5(14), 2018, pp. 28427-28437.

9. M. R. Sanjay, G. R. Arpitha \& B. Yogesha, "Study on mechanical properties of natural-glass fibre reinforced polymer hybrid composites: A review". Materials today: proceedings, 2(4-5), 2018, pp. 2959-2967.

10. S. Vigneshwaran, M. Uthayakumar \& V. Arumugaprabu, "Solid 
particle erosion study on redmud-an industrial waste reinforced sisal/polyester hybrid composite". Materials Research Express, 2019.

11. R. D. J. Johnson, V. Arumugaprabu, M. P. Kumar \& K. Dheeraj, "Solid particle erosion on the biochar filled hybrid vinyl ester composite". In AIP Conference Proceedings - AIP Publishing, Vol. 2057, No. 1, 2019, pp. 020064.

12. R. Gujjala, S. Ojha, S. K. Acharya \& S. K. Pal, "Mechanical properties of woven jute-glass hybrid-reinforced epoxy composite". Journal of Composite Materials, 48(28), 2014, 3445-3455.

13. P. S. Shin, J. H. Kim, H. S. Park, Y. M. Baek \& D. J. Kwon, "Mechanical, Interfacial and Thermal Properties of Different Chemical Structures of Epoxy Resin". J Powder Metall Min, 6(169), 2, 2017.

14. J. Tang, H. Zhou, Y. Liang, X. Shi, X. Yang \& J. Zhang, "Properties of graphene oxide/epoxy resin composites". Journal of Nanomaterials, 2014.

15. M. Singla \& V. Chawla, "Mechanical properties of epoxy resin-fly ash composite". Journal of minerals and materials characterization and engineering, 9(03), 199, 2010.

16. F. H. Latief, A. Chafidz, H. Junaedi, A. Alfozan \& R. Khan, "Effect of Alumina Contents on the Physicomechanical Properties of Alumina Reinforced Polyester Composites". Advances in Polymer Technology, 2019.

17. H. N. Dhakal, Z. Y. Zhang \& M. O. W. Richardson, "Effect of water absorption on the mechanical properties of hemp fibre reinforced unsaturated polyester composites". Composites science and technology, 67(7-8), 2007, pp. 1674-1683.

18. P. A. Sreekumar, S. P. Thomas, J. Marc Saiter, K. Joseph, G. Unnikrishnan \& S. Thomas, "Effect of fiber surface modification on the mechanical and water absorption characteristics of sisal/polyester composites fabricated by resin transfer molding". Composites Part A: Applied Science and Manufacturing, 40(11), 2009, pp. 1777-1784.

19. P. Kaushik, J. Jaivir \& K. Mittal, “Analysis of mechanical properties of jute fiber strengthened epoxy/polyester composites". Engineering Solid Mechanics, 5(2), 2017, pp. 103-112.

20. G. G. Kumar, G. Ranganath \& M. Sakthivel, "Fabrication of Industrial Safety Helmet from E-Waste". Asian Journal of Research in Social Sciences and Humanities, 6(8), 2016, pp. 1964-1973.

21. J. Thanikachalam, N. Vasiraja \& V. Vignesh, "Evaluation on Properties of Industrial Workers Safety Helmet Using Natural Hybrid Composite (No. 2018-28-0049). SAE Technical Paper, 2018.

22. P. K. Bajpai, K. Ram, L. K. Gahlot \& V. K. Jha, "Fabrication of Glass/Jute/Epoxy Composite Based Industrial Safety Helmet". Materials Today: Proceedings, 5(2), 2018, pp. 8699-8706.

23. M. Rafiquzzaman, M. T. Isalm \& M. F. Hossain, "Fabrication and performance test of glass-bamboo fiber based industry safety helmet". Am J Mech Mater Eng, 1, 2017, pp. 20-25.

24. L. U. Devi, S. S. Bhagawan \& S. Thomas, S. "Mechanical properties of pineapple leaf fiber - reinforced polyester composites". Journal of Applied Polymer Science, 64(9), 1997 pp. 1739-1748.

25. J. Rout, S. S. Tripathy, M. Misra, A. K. Mohanty \& S. K. Nayak, "The influence of fiber surface modification on the mechanical properties of coir - polyester composites". Polymer Composites, 22(4), 2001, pp. 468-476.

26. M. H. JA, M. A. Majid, M. Afendi, H. F. A. Marzuki, I. Fahmi \& A. G. Gibson, "Mechanical properties of Napier grass fibre/polyester composites". Composite Structures, 136, 2016, pp. 1-10.

\section{AUTHORS PROFILE}

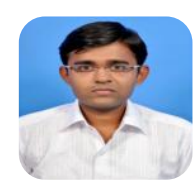

Mr. S. Ajith has completed his graduation and post-graduation from KTVR Knowledge Park for Engineering \& Technology and University Departments of Anna University respectively. Currently he is a research scholar at Kalasalingam

Academy of Research and Education, India.

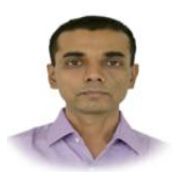

Dr. C.Sivapragasam has completed his graduation and post-graduation from IIT-Roorkee and IIT-Delhi respectively. He completed his $\mathrm{PhD}$ from NUS, Singapore. He has 2 years of industry experience and more than 17 years of teaching experience. He has completed 3 sponsored research projects from various funding agencies and published more than 70 papers in peer reviewed journals and conferences.

Dr. V. Arumugaprabu has completed his graduation in Mechanical Engineering and post-graduation in CAD/CAM from Arulmigu Kalasalingam College of Engineering and Mepco Schlenk Engineering College respectively. He completed his $\mathrm{PhD}$ from Kalasalingam Academy of Research and Education, India. He has 12 years of teaching experience. He has completed 1 sponsored research project from funding agencies and published more than 80 papers in peer reviewed journals and conferences.

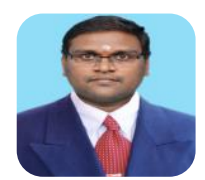

